\title{
The Effect of WhatsApp Chat Group in Enhancing EFL Learners' Verbal Interaction outside Classroom Contexts
}

\author{
Amir Abdalla Minalla ${ }^{1}$ \\ ${ }^{1}$ Department of Languages and Translation, Faculty of Education and Arts, University of Tabuk /Tayma Branch, \\ Saudi Arabia \\ Correspondence: Amir Abdalla Minalla, Department of Languages and Translation, Faculty of Education and \\ Arts, University of Tabuk /Tayma Branch, Saudi Arabia. E-mail: Amirdarnile@gmail.com
}

\author{
Received: December 9, 2017 Accepted: January 30, 2018 Online Published: February 1, 2018 \\ doi: 10.5539/elt.v11n3p1 URL: http://doi.org/10.5539/elt.v11n3p1
}

\begin{abstract}
This study was mainly conducted to examine the possibility of utilizing 'WhatsApp Group' in enhancing EFL learners' verbal interaction. To do this experimental and descriptive methods were used to achieve the objective of this study. A questionnaire and pre- and post- test were adopted as tools for data collection. Samples of two groups (experimental \& control) were randomly selected. The results were analyzed with SPSS. Both groups were taught the same content using the traditional way integrated with WhatsApp Chat groups via text message as communicative platforms for practicing outside classroom contexts for what have been taught in the traditional class. However, the participants of experimental group were restrictively interacted via voice messages while the participants of control group were only interacted via text messages. The analysis of the data revealed that the participants who underwent the voice messages on WhattsApp treatment significantly outperformed those who underwent in text messages on WhatsApp. Hence, utilizing voice messages on WhatsApp chat group can be recommended as an efficient technique in enhancing EFL learners' verbal interactions outside classroom contexts. Because EFL traditional classroom is no longer more appropriate in offering sufficient opportunities for EFL learners' verbal interaction.
\end{abstract}

Keyworsd: interaction, veral, contexts, messages, WhatsApp

\section{Introduction}

Without a doubt, we are in the center of a monumental technological paradigm shift, one which will eventually change the way that all instructors teach and the way students learn (Jensen, 1993, cited in Khalili and Baradaran (2009). In recent years, communication via mobile messaging applications (such as LINE, INSTAGRAM, in particular WhatsApp...) has gained increasing popularity among young users in Arab countries.This social network has opened up new opportunities of interaction and collaboration between teachers and learners especially in language learning. So, with the growth of WhattsApp popularity, WhatsApp groups may contribute in expanding opportunities of verbal interaction through voice message. It notice that, these groups are widely used in social communications and many others but as I am an English language teacher and supervisor and still in both Arab countries Sudan and Kingdom of Saudi Arabia, few people use them for education purpose such as learning English language.These groups attain wide interactive collaborative learning outside classroom contexts. On the contrary, traditional learning and communication are interrupted by many barriers such as time constraint, psychological factors, large number of students (Kitano, 2001). A research into the role of such instant and text messaging technologies in education has revealed their positive effects on providing platforms for socializing, sharing information, and communicating (Sweeny, 2010). One of the Arab EFL teachers' challenges that to find what make practicing English verbally available and common via utilizing modern social media. Therefore, creating a new mobile platform for verbal communication present much help for Arab EFL learners for practicing English orally particularly smart phones are becoming increasingly popular and WhatsApp is available for almost all Smartphone. Moreover, WhatsApp application offers features, which can be used for learning speaking. Students can hold discussion on chatroom on the WhatsApp group by recording their voices and send to the group. The students can find the topic of discussion themselves or the teacher can also give a suitable topic for learning activities. Therefore, expanding verbal communication opportunities increase EFL learners' engagement in practicing English so that promote their oral production. This article attempt to examine the effect of 
utilization of theseWhatsApp groups in promoting EFL learners' verbal interaction. These groups and many others are means to enhance learning language generally and the verbal interactions in particular.

\subsection{Statement of the Problem}

As researcher have been an English language teacher in Kingdom of Saudi Arabia, noticed that the quality of verbal production of Saudi EFL learners is not satisfactory. Some apparent reasons that interrupt practicing English verbally in the traditional classroom such as time constraint, the large number of students in a language classroom (preparatory years class)as well as students are influenced by uncontrolled anxiety when they speak in front of their classmates (Kitano, 2001). So, this study is an attempts to find out the effect of WhatsApp group chat room in enhancing verbal interactions outside classroom context.

\subsection{Objective of the Study}

This study mainly aims to find out verbal communicative platform outside classroom contexts that to enhance EFL learners' verbal interaction. More specifically, it aims at finding out ways that could be integrated with traditional instruction for supporting EFL learners' verbal interactions outside classroom contexts that is timeand place-independent.

\subsection{Question of the Study}

To what extent utilizingvoice message chat on WhatsApp Groupcould enhanceEFL learners' verbalinteraction outside classroom contexts?

\section{Literature Review}

This section provides a brief overview of literature and seven research studies that are related to the use of social networks to promote English Language learning are reviewed. The seven studies investigated the benefits of applying different social media applications to improve learners' performance in English language.

One of the most difficult challenges in teaching a foreign language is finding ways to help students improve their oral fluency. This is especially true in countries where students generally share a common mother tongue and have little or no exposure to English outside the classroom (Khalili \& Baradaran, 2009). So, online communication is time- and place-independent. Learners communicate with each other anywhere and anytime as long as there is an access to the internet (Zayed, 2016). The prevalence of network connections have helped to shift gradually learning settings from the traditional face-to-face classroom to online learning environment, where learners interact with the instructor and with other learners (Bataineh, 2014).

Students nowadays have strong passion towards the smart mobile phones with all their smart applications. So, English language teachers can use the mobile phones, from each now and then, to increase the students' motivation. Nowdays students are so fond of mobile phones; they are interested to own the most up-dated smart mobile phones with latest applications in the market. There is trend to make benefit of this passion by adopting mobile phones in English classes (Zayed, 2016).

An advantages of online communication comparing to face-to-face interaction as follows:(a) the exchanges were viewed as real, not pedagogical; (b) learners developed free and spontaneous, though not flawless communication while using highly complex structures and vocabulary; (c) learners expressed deep satisfaction at being able to manage themselves as leaders and contributors in the target language; and (d) learners benefited substantially from the increased opportunity to practice target language outside the classroom Warschauer (1997).Through chatting, learners of a language can communicate inexpensively and quickly with other learners or speakers of the target language all over the world (Khalili \& Baradaran, 2009).

\subsection{Feedbackon Some Related Previous Studies}

It is worth mentioning that all the following studies wereresearch papers research followed experimental studies that used control and experimental group method for data collection.These studies had come out with the common conclusion that utilizing social network in teaching and learning was more effective and appropriate for the students nowadays. These common results were briefly reviewed as follows:

Khalili and Baradaran (2009) conducted a study that is to investigate the effectiveness of using chat rooms as a newly-developed technique on the oral fluency of EFL learners. The findings revealed that the learners who underwent the chat room treatment significantly outperformed those who did not in terms of oral fluency.Hence, using chat rooms in the EFL context can be recommended as an efficient technique in improving this attribute among EFL learners.

Alfaki and Alharthy (2014) conducted a study aimed at investigating the effect of using social websites on 
English language learners' performance in English. The study showed that learning through social networks was more effective than traditional learning which looked to the classrooms a place of gaining information as they offer a chance for learners to get rid of the tension of classroom activities due to the fear of making mistakes or any negative behavior. Also, they revealed that collaboration was a useful learning strategy in improving one's foreign language.

In his study, Bataineh (2014) aimed at investigating the effect of using audiovisual chat on the improvement of tenth grade students' fluency and productivity of authentic oral texts in English, in the first semester of the scholastic year 2013/2014.The study revealed that, audiovisual chat is found to offer a great opportunity in teaching aspects of fluency. Students of experimental group achieved better results on the fluency test in audiovisual chat environment than other student of controlled group those who were taught aspects of fluency traditionally.

The study which is conducted by Rodrigues and Vethamani (2015) aimed to investigate the comparative results and learners' feedback on the effectiveness of the English Proficiency in Conversation (EPiC) online learning programme that influences the speaking performance of the $\mathrm{EPiC}$ group and non-EPiC group students in a 12-week Intensive English Programme (IEN). The result shows that showed that the EPiC group performed better than the non-EPiC group in terms of improvement in speaking grades, and vocabulary and listening skills despite unstable Internet connection.

Alhawiti, (2015), conducted study aimed to look at the effect of the WhatsApp method of learning English for Specific Purposes (ESP) students' achievement at the community college of Tabuk in the academic year 2013/2014. The findings revealed that the students in the experimental group showed significantly higher progress in ESP posttest terminology. The differences between the mean scores and the standard deviations of the two groups on the posttest were 52.83 for the control group and 67.50 for the experimental group, which mean that the results were statistically significant. WhatsApp-based group platform was more effective than the conventional instruction mode, because the conventional group acquired the lowest degree of significance compared with the experimental group.

A study which is conducted by Zayed (2016) aimed at increasing the students' motivation through utilizing mobile phone in teaching and learning process. The study revealed that social Networks offer a chance for learners to get rid of the tension of classroom activities due to the fear of making mistakes or any negative behavior. It also agrees with the theory of connectivism that beginning to prevail as a result of this new Digital World, information age, internet applications and the new ways and multi-media through which digital natives receive, send information and gain knowledge. Nowadays learners live amidst many digital tools and software applications and they own computes and portable devices such as smart phones with their ever renewable applications at hand every minute.

A study conducted by Ta'amneh (2017) aimed to find the effect of using "WhatsApp messenger" in learning English language among university students during the academic year 2015/2016. The findings showed that integrating the WhatsApp application in teaching English language improved the EFL learnersabilities. It also showed that English lessons can be learned more effectively through integrating technological applications such as WhatsApp messenger in learning English than the traditional methods.

\section{Methodology}

\subsection{Study Design}

The study used both experimental and descriptive methods. Thus, both qualitative and quantitative data analysis were used to provide a better chance to attain reliable findings.

\subsection{Subjects}

The population of the study are Saudi Arab first year university students who almost at the same age as well as having the same background knowledge of English. The purposively selected sample was students at University of Tabuk, Tayma branch in the first semester of the academic year 2017/2018. The total number was thirty, divided into two groups, group'A' and group'B'. Group 'A' consisted of fifteen and represented the control group, while Group 'B' consisted of fifteen also, represented the experimental group. Participants of both groups were almost in the same age as well as having the same background knowledge of English. In this respects, verbal interaction level of both groups was estimated as beginners.

The participants of both groups had been studying general English (Headway Plus -Elementary) as university requirement course so they were taught the same content. They were taught in traditional way integrated with WhatsApp chat group only using text messages which was designed for practicing to what they have been taught 
in traditional class. But, for the purpose of treatment, each group of both groups has its own WhatsApp chat group, as the experimental group's participants were restrictively tended to be interacted via voice messages. While control group's participants were to be interacted via text messages only.

Few number of participants in each group (15) can be justified by enabling the participants in each group of having well chance in interaction and moreover well managing and supervision. In this respect, it is worth mentioning that the instructor of the course was the researcher himself and who was the supervisor of both WhatsApp groups.

\subsection{Instruments}

The instruments consisted of oral achievement tests (pre and post) and an questionnaire. Pre-test was to determine whether participants are homogeneous in verbal ability of English language speaking. This verbal test consist of 12 questions, as 8 open ended questions and 4 close ended questions. To be statistically acceptable, test and retest technique was used to measure a reliability of the test. In this respect, a pilot sample of (13) students from the population of the study. It was found that correlation coefficient of the two test was 0.82 which was acceptable for the purposes of the research. Finally, another verbal test as the posttest was administered. This test also consisted of 12 open ended questions, as 8 open ended questions and 4 closed ended questions. The only difference between the post and pre tests was that the sequence of the questions had been changed in order to avoid practice effect on the part of the participants.

Another an instrument was a questionnaire which contained five items. It was designed to check participants 'attitudes of experimental group toward utilizing voice message on WhatsApp chat group as platform to practice English language verbally outside classroom contexts. Statistic evidence is computed by Pearson's correlation, R $=0.84$, Validity $=\sqrt{\text { reliability }}=0.92$. So, these results are statistically accepted. Moreover, both instruments were distributed to be judged by five ELT experts. On the light of their comments, the instruments were put in their final draft.

\subsection{Procedure}

All participants of experimental and control groups were administered to the pre-test after a month prior to the beginning of the instruction. The participants had an hour per day and they were taught via traditional methods integrated with WhatsApp chat group, which only used text message. In this test, individually, each participant was interviewed to provide oral answers for the interviewees' questions which were developed from the content that was taught in traditional class and practiced via text message on the WhatsApp chat group. After administration and for the purpose of treatment, participants of both groups were taught same content via traditional methods with an integration of WhatsApp chat group. They had a lecture per day for a month taught by the same instructor (researcher). However, for the purpose of interaction outside classroom contexts, two separated WhatsApp chap groups were made for the two groups (control and experimental). Thus, participants of experimental group were restrictively assigned to be interacted via voice messages. While participants of control group were tended to be interacted via text messages only. At the end of the treatment period (two months), all the participants were subjected to the post oral test. Afterwards, the questionnaire written in participants' mother tongue language (Arabic) was distributed only to the participants of experimental group.

\section{Data Analysis}

The overall analysis of the comparison between the pre- and post-tests and the questionnaire results, it was found that the control group attained no progress while experimental group do much progress which is due to the new teaching program through which students practice language verbally via voice message chat on WhatsApp group. The students do practice for what they had routinely taught.

\subsection{Tests' Analysis}

Table 1. Pre- test analysis

\begin{tabular}{llllll}
\hline Group & N & Mean & Std Deviation & t & Sig(2- tailed) \\
\hline Experimental Group & 15 & 2.13 & .516 & .000 & 1.000 \\
Control Group & 15 & 2.13 & .640 & .000 & 1.000 \\
\hline
\end{tabular}

In Table 1, it was found that there was no significance difference in the mean of scores between control and experimental groups in the pre-tests that because the significance $(\mathrm{P})$ was greater than 0.05 . 
Table 2. Post-test analysis

\begin{tabular}{lllcll}
\hline Group & $\mathbf{N}$ & Mean & Std Deviation & t & Sig(2- tailed) \\
\hline Experimental Group & 15 & 2.20 & .561 & .000 & $-23.684-$ \\
Control Group & 15 & 9.53 & 1.060 & .000 & $-23.684-$ \\
\hline
\end{tabular}

Table 2 statistical result shown that there was a significance difference in the mean of scores between control and experimental groups in the post tests because the significance $(\mathrm{P})$ was less that $(0.05)$ which means there was significance differences in favor of experimental group which due to utilizing voice message chat on WhatsApp group for practicing English outside classroom context verbally.

\subsection{Questionnaire Analysis}

The questionnaire mainlyaims to check experimental group participants' attitudes towards practicing English language verbally outside classroom contexts via voice message chat on WhatsApp group.

Table 3. The questionnaire

\begin{tabular}{|c|c|c|c|c|c|}
\hline \multirow[t]{2}{*}{ No. } & \multirow[t]{2}{*}{ Questions } & \multicolumn{2}{|l|}{ yes } & \multicolumn{2}{|l|}{ No } \\
\hline & & No. & $\%$ & No. & $\%$ \\
\hline 1 & $\begin{array}{l}\text { Is it appropriate platform for sharing a knowledge of } \\
\text { language collaboratively? }\end{array}$ & 13 & $86.7 \%$ & 2 & $13.3 \%$ \\
\hline 2 & $\begin{array}{l}\text { Is it appropriate platform for EFL verbal interaction } \\
\text { outside classroom contexts? }\end{array}$ & 14 & $93.3 \%$ & 1 & $6.7 \%$ \\
\hline 3 & $\begin{array}{l}\text { Is it appropriate platform for practicing for what you have } \\
\text { routinely learnt in the classroom contexts? }\end{array}$ & 12 & $80 \%$ & 3 & $20 \%$ \\
\hline 4 & $\begin{array}{l}\text { Is it appropriate platform for further practicing of the } \\
\text { target language? }\end{array}$ & 13 & $86.7 \%$ & 2 & $13.3 \%$ \\
\hline 5 & $\begin{array}{l}\text { Is it appropriate platform for supporting your present } \\
\text { language attitudes? }\end{array}$ & 11 & $73.3 \%$ & 4 & $26.7 \%$ \\
\hline
\end{tabular}

Question1: reported that $86 \%$ of the respondents answer positively that utilizing voice message chat on WhatsApp Group could enable them of share language knowledge collaboratively. This is a strong indication that the method establishesverbal collaborative interaction so better practicefor the target language.

Question2: showed that $93 \%$ of the respondents considered the methodisappropriate platform for practicing language outside classroom. While $6 \%$ of the respondents responded negatively. It is means that the method is appropriate for filling the gap of verbal interaction outside classroom contexts.

Question 3: reported that $80 \%$ participants responded positively which indicated that it is appropriate for practicing for what students have routinely learnt in their classrooms. While $20 \%$ of the participants responded negatively, which indicated themethod is inappropriate for practicing for what have students been learnt in the classroom contexts. The majority supports the method is appropriate for practicing for what students have been learnt inside classroom context. Therefore, teacher could check his students' progress for what they have learned routinely. Moreover, it allows teacher to switch an interaction in a time out of classroom contexts.

Question4: 86\% of the participants response positively which reported that the suggested method is appropriate for further language practice while $13 \%$ of the participants do not think so. The majority supportthat; it can be utilized for adapting language for many purposes other than classroom materials.

Question 5: 73\% of the respondents reported that it could be appropriate for their present attitudes while 26\% of the participants responded negatively. The majority think it is appropriate for their current attitudes of language.

\section{Results' Discussion}

The results of this study showed that there was a difference in the interaction thus the achievement of the experimental group is better than the achievement of control group on the post-test. More specifically, in the 
means of the scores in the two tests of both groups, it was found that the significance of both groups in the pre-tests was (1.000) so greater that $(0.05)$ which indicates that there was no significant difference between both groups. However, in post-test of both groups, it was found that the significance was (.000) so less than (0.05) which indicates that there was significance difference that in favor of experimental group due to the technique used for practicing English verbally outside classroom contexts. It was clear these results were in favor of the experimental group and has an advantage comparing with the control group. So, the progress in the verbal interaction of the students in the experimental group could be referred to the new method that employed in the teaching process. These results confirmed that using WhatsApp messenger affected the learning process positively especially voice message chat. As for questionnaire's results of all questions come out with the positive results in favor of utilizing voice message chat on WhatsApp for enhancing verbal interaction outside classroom contexts. Thus, the majority of experimental group participants express their approval of using voice message chat on WhatsApp for practicing language verbally. The results of present study comfirms the results of these studies as follows: Alfaki and Alharthy (2014), Amry (2014), Cavus and Ibrahim's (2008), AbdAlfattah (2015), Alhawiti (2015), Cakir (2015) and Attewell (2005).

\section{Conclusion}

In spite of facilities and the multi-channels of learning English but EFL learners still, prove their inability of expressing themselves verbally well. Moreover, one of the most EFL teachers' challenges that to find an effective teaching and learning techniques that could engage EFL learners in a spontaneous verbal interaction.

This study mainly aims to find out verbal communicative platform outside classroom contexts to enhance EFL learners' verbal interaction. The findings of this indicated that the experimental group that used a combination methods (WhatsApp voice messagge and traditional) was better than the control group which also used combinations methods however WhatsApp text messages with traditional method. It can be concluded that utilizing voice message chat on WhatsApp is an effective technique in enhancing EFL learners' verbal interaction. In addition, it creates appropriate platform for students to practice language verbally well outside classroom contexts for what they have learnt in the classroom contexts. Moreover, the participants express their approval and show positive attitudes toward it.

Depending on the obtained results, the study recommends that EFL teachers particularly those who teach intermediate and advance level should adopt voice message chat on WhatsApp group as basic platform for expanding practice English language verbally outside classroom contexts. In addition, it recommends that some adapted lessons should be specified to be discussed on WhatsApp group which may increase students' engagement.

The researcher obviously observed that the participants in the experimental group were used to express themselves freely in the chat rooms without that the very common anxiety and fear of making mistakes and even without any interference with and interruptions of others' speech. This sense of security and other reasons may help them to accomplish more and get them from good to better.

Also they were used to interact at different times but rush hours of interaction were in the evening and at night so that means WhatsApp application offers verbal interactions outside classroom contexts that is time- and place-independent.

Also it was a chance for the teacher to use the students' records again to check their language progress. So, based on teacher's notes, adaptation, reinforcing weak points and confirming on strong points all these can be taken into account for more interactive teaching and learning processes.

\section{Reference}

Alhawiti, M. (2015). The Effect of Mobile Language Learning on ESP Students' Achievement. https://doi.org/10.15341/jmer(2155-7993)/03.05.2015/007

Alfaki, I., \& Alharthy, K. (2014). Towards a Digital World: Using Social Networks to Promote Learner's Language. Retrieved from https://pdfs.semanticscholar.org/adb4/5f0205a8f33d674d96d782412534a 7767406.pdf.

Bataineh, A. (2014). The Effect of Using Audiovisual Chat on Developing English as a Foreign Language Learners' Fluency and Productivity of Authentic Oral Texts. https://doi.org/10.5296/ijl.v6i3.5563

Khalili. A., \& Baradaran, A. (2009). The Impact of Online Chatting on EFL Learners' Oral Fluency.

Kitano, K. (2001). Anxiety in the Japanese college classroom. Retrieved from http://onlinelibrary.wiley.com/doi/10.1111/0026-7902.00125/epdf 
Rodrigues, P., \& Vethamani, M. (2015). The Impact of Online Learning in the Development of Speaking Skills. Retrieved from http://www.taylors.edu.my/jire/downloads/vol5_04.pdf

Sweeny, S. M. (2010). Writing for the instant messaging and text messaging generation: Using new literacies to support writing instruction. Journal of Adolescent \& Adult Literacy, 54, 121-130. https://doi.org/10.1598/JAAL.54.2.4

Ta'amneh, M. (2017). The Effect of Using WhatsApp Messenger in Learning English Language among University Students. https://doi.org/10.5296/ire.v5i1.10801

Warschauer, M. (1997). Computer-Mediated Collaborative Learning: Theory and Practice. https://doi.org/10.1111/j.1540-4781.1997.tb05514.x

Zayed, N. (2016). Special Designed Activities for Learning English Language through the Application of WhatsApp. https://doi.org/10.5539/elt.v9n2p199

\section{Copyrights}

Copyright for this article is retained by the author(s), with first publication rights granted to the journal.

This is an open-access article distributed under the terms and conditions of the Creative Commons Attribution license (http://creativecommons.org/licenses/by/4.0/). 